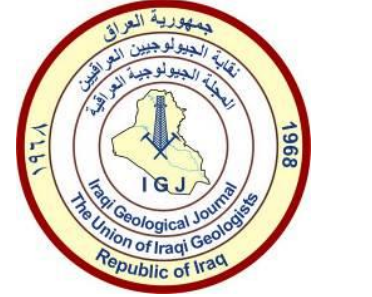

Iraqi Geological Journal

Journal homepage: https://www.igj-iraq.org

\title{
New Equations to Determine Shear Velocity from Compressional Velocity in Hf-2 Well, Halfaya Oil Field
}

\author{
Ahmed Al-Banna ${ }^{1, *}$, Hiba Tareq ${ }^{1}$ and Ghazi Al-Sharaa ${ }^{2}$ \\ Department of Geology, College of Science, University of Baghdad, Baghdad, Iraq \\ Oil Exploration Company, Iraq \\ Correspondence: geobanna1955@yahoo.com
}

Received:

17 July 2021

Accepted:

30 November 2021

Published:

28 February 2022

\begin{abstract}
The most important characters of the rock formations are shear and compression velocities, which are used to calculate elastic moduli. The geomechanical properties can be used to evaluate reservoir stability or to calibrate velocity and time/depth conversion, synthetic seismogram and other important applications. The aim of this study is to use the first order least square method to obtain an empirical equation to determine the shear velocity from compressional velocity for Mishrif, Rumaila, Ahmadi, and Mauddud formations in Hf-2 well. The obtained equations depend on sonic log and dipole shear sonic imager data of Hf2 well and use Techlog software. The results from the obtained equations in comparison with those results of Green Castagna equation and measured data of dipole shear sonic imager of shear velocity for Mishrif, Rumiala and Mauddud formations. It is found from the comparison that the result is consistent each other's. The consistent reflect the reality of shear waves values obtained in these formations. The comparison in Ahmadi formation also shows a consistent result for the obtained equations but it shows some differences from the dipole shear sonic imager and shear velocity reference values. The authors believed that the difference in some values of the Ahmadi Formation may be due to the high shale volume in comparison to the other formations.
\end{abstract}

Keywords: Compressional velocity; Shear velocity; Halfaya Oil Field; Castagna Equation; First order least square method

\section{Introduction}

The well log data are very useful in processing stage of evaluation the geological formations. The importance of using shear velocity is ranging from seismic exploration, calculation of petrophysical properties and evaluation of the well stability. Sometimes not all logs are available, for example the dipole shear sonic imager (DSI) (Rezaee et al. 2006, Amunobereton-ari et al. 2010). The DSI have both monopole and dipole sonic acquisition abilities for the dependable acoustic measurement of compressional, shear, and Stoneley slowness's. The transmitter part is composed of a piezoelectric monopole transmitter and two electrodynamics dipole transmitters that are perpendicular to each other. In order to excite compressional- and shear-wave propagation in the formation; the electric pulse at sonic frequencies is used in the monopole transmitter (Al-Malikee and Al-Najim, 2018). In fact, this tool is not available in all wells mainly in old wells. When the direct measurements are absent; shear-

DOI: $\underline{10.46717 / i g j .55 .1 B .4 M s-2022-02-20}$ 
wave velocity is usually estimated from P-wave velocity using empirical equations (Castagna et al., 1985, Greenberg and Castagna, 1992) or theoretical relationships (Krief et al., 1990, Eskandari et al., 2004, Brocher, 2005). These methods have some disadvantages and it can only be useful to give good results in regions where they can be determined. Other regions are in need for studying new relations which may be different from these equations by some amount depending on the geological conditions in the region. The dipole shear sonic imager for well (Hf-2) as one of the Halfaya oil fields located in the south of Iraq, which is used to calculate compression and shear velocities relationships for four carbonate formations from cretaceous age, which are Mishrif, Rumiala, Ahmadi and Mauddud formations, then calibrate these velocities to predict accurate equations compatible with Iraqi conditions. Halfaya oilfield was discovered in 1976 by well HF-1. The Well HF002-N004 was proposed as a horizontal development well to test the hydrocarbon potential in Halfaya area, the structure was defined by 2D seismic data between 1974 and 1980; up to 2009, seven wells have been drilled and significant oil accumulations have been discovered in the Tertiary Jeribe, Euphrates, Upper Kirkuk formations and the Cretaceous Sadi, Tanuma, Khasib, Mishrif, Nahr Umr, and Yamama formation (M.O.C., 2012).

There are several previous studies which used different methods to calculate shear velocity (Vs) from compressional velocity (Vp). Opiriyabo et al. (2014) calculated Vs from Vp using Greenberg and Castagna (1992) equation for AK-1 and AK-2 wells in the Niger Delta Basin of Nigeria; the results of this study showed that Vp and Vs increased with depth for all sand and shale lithologies while Vs was larger in shale compared to sand formations. They plotted a linear trend for each type of velocity with depth as well as a linear trend relation between Vp and Vs. Adjei et al. (2020) studied the Tano North Field located in southwestern part of Gulf of Guinea, they calculated the shear wave velocity from the compressional velocity by using four different methods to estimate the shear wave velocity under three different conditions. The final results were estimated depending on obtained coefficient of determination and average absolute percent relative error between real and predicted values of shear wave velocity. Majeed and Alhaleem (2020) used a statistical method in which regression analysis equations were employed to predict shear wave velocities from well logs of a productive carbonate (limestone) of Mishrif Formation in Amara oil field southeast of Iraq; this method can estimate shear wave velocity in carbonate rocks with a correlation coefficient of close to unity.The aim of this study is to use the first order least square method to obtain an empirical equation to determine the Vs , Vp for Mishrif, Rumiala, Ahmadi, and Mauddud formations in Hf-2 well.

\section{Location of the Study Area}

Halfaya oil field is located in Messan Governorate, southern of Iraq; it is located about $35 \mathrm{~km}$ southeast Amara City (Fig.1). The well HF002 almost is located on the anticline of the structure crest, $2.1 \mathrm{~km}$ to the north of the well HF-8 and $0.68 \mathrm{~km}$ northwest to the well HF-005 (M.O.C, 2012).

\section{Stratigraphic Section of Hf-2}

Halfaya Oilfield is a gentle elongated anticline, about $38 \mathrm{~km}$ long and $12 \mathrm{~km}$ wide, trending NWSE to NWW-SEE. Formations penetrated by wells in Halfaya Oilfield include Cretaceous and Tertiary strata deposited in marine environment (Fig.2). In Halfaya area there are 4 major regional unconformable surfaces, namely tops of Shuaiba, Mauddud, Mishrif and Aaliji. The Mishrif Formation consists mainly of limestone and grainstone while the major structure of Rumaila Formation is dense limestone with some argillaceous component, and Ahmadi Formation mainly consists of claystone interbedded with limestone and lastly the chalky limestone constitutes the main part of Mauddud Formation. (M.O.C., 2012) (Aqrawi et al. 2010). 


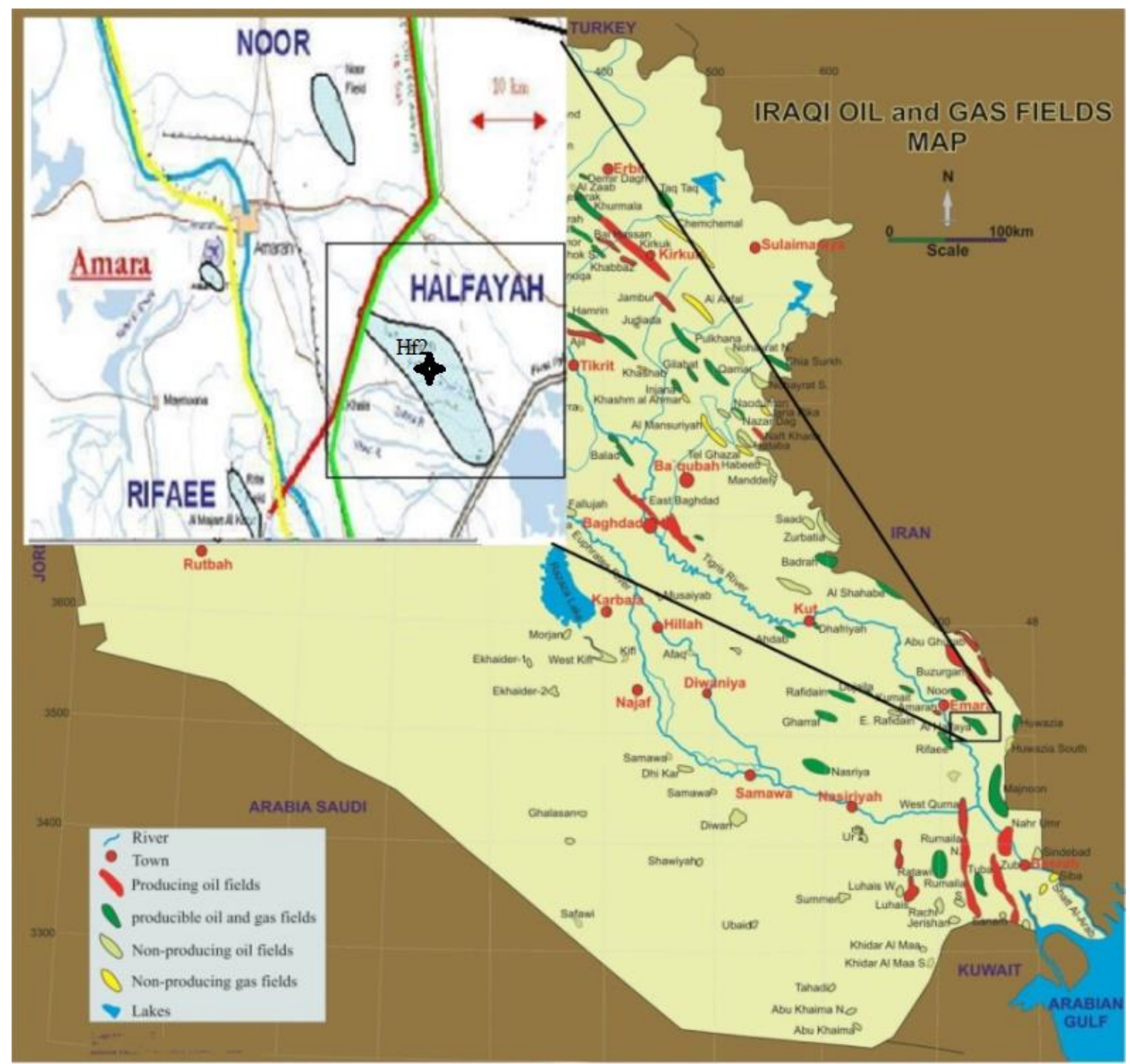

Fig.1. Location map of the study area (Al-Khafaji et al. 2013)

\section{Materials and Methods}

The presence of each type of sound velocities values in the logs set for any exploration well is very important because they are considered as keys for calculating Poisson ratio and lithology type and many other different physical properties. The available well log data are the Vp and Vs values of Hf-2 well. The data of Mishrif, Rumaila, Ahmadi and Mauddud formations of cretaceous age were used to obtain a regression relationship between $\mathrm{Vp}$ and $\mathrm{Vs}$ for these formations. Regression define as a statistical method used to determine the relation between two variables on of them is known and generally represented in $\mathrm{x}$ axes and the other unknown represented in y axes, there are three types of regression are linear regression, multiple linear regression and non-linear regression methods (Gallo, 2015). The second aim is comparing the results of the determined relationship with the equation of Greenberg and Castagna (1992). The Greenberg and Castagna depends on determination of Vs from Vp using three equations (1, 2 and 3) for different lithologies (Greenberg andCastagna, 1992). The Castagna equations are

$$
\begin{aligned}
& \text { Vs }=-0.05508 \mathrm{Vp}^{2}+1.01677 \mathrm{Vp}-1.03049 \text { (Limestone) } \\
& \text { Vs }=0.8042 \mathrm{Vp}-0.5588 \text { (Sandstone) } \\
& \text { Vs }=0.76969-0.86735 \text { (Shale) }
\end{aligned}
$$




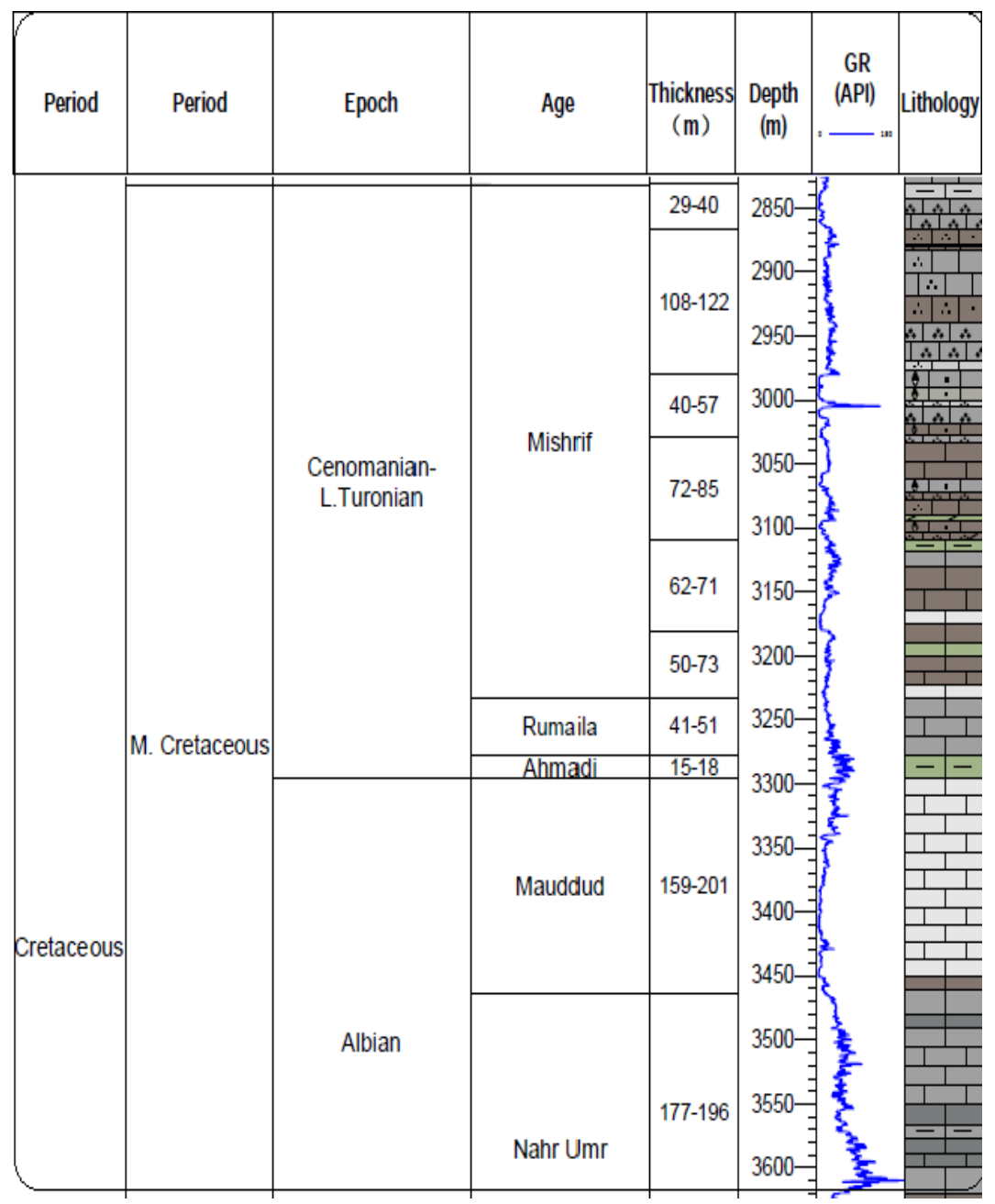

Fig.2. Stratigraphic section of the Halfaya oil field Hf-2 (M.O.C, 2013)

\section{Results and Discussion}

The empirical relationship equations between the $\mathrm{Vp}$ and the $\mathrm{Vs}$ were determined using first order least square fitting for Mishrif, Rumaila, Ahmadi and Mauddud formations in $\mathrm{Hf}-2$ well, (Figs. 3, 4, 5 , 6 and 7). The obtained equations and their regressions were tabulated in Table1. Figs. 8, 9, 10 and 11 show the final computer interpretation for this study as the first column reflects compressional transit time of DT in pink Vp in purple color line, the second column reflects Vs measured by four methods while the red line represents shear velocity which is calculated from formation predicted equation; the pink line represents shear velocity which is calculated from general predicted equation for all four formations in the well of Hf-2; the green line represents the shear velocity that is measured from well DSI log which exists in this well and is read from field directly and is considered as a reference to calibrate all other three shear velocities. Finally, the blue line represents shear velocity measured using empirical Greenberg -Castagna equation using Techlog 2015 software. The third column reflects the shale volume that is calculated using gamma ray log. The results from these figures indicate that all three shear velocities measured from spatial formation equation, all formation equation and Greenberg -Castagna equation are consistent and very close to the DSI shear velocity line in the Mishrif Formation as seen in Fig.8; in the Rumiala Formation they are close to the reference shear velocity (Fig.9), in the Mauddud Formation, they are close to each other but the shear velocity that is measured from formation equation is nearest to the reference shear velocity as shown in Fig.11; in the Ahmadi Formation, the three measured velocities are consistent but there are differences between them and DSI Vs which may 
be caused by the high percentage of shale volume in this formation and high porosities compared with other formations We can suggest that the predicted equation in this study can be used to calculate Vs from Vp in the Mishrif, Rumiala and Mauddud formations in the Halfaya oilfield.

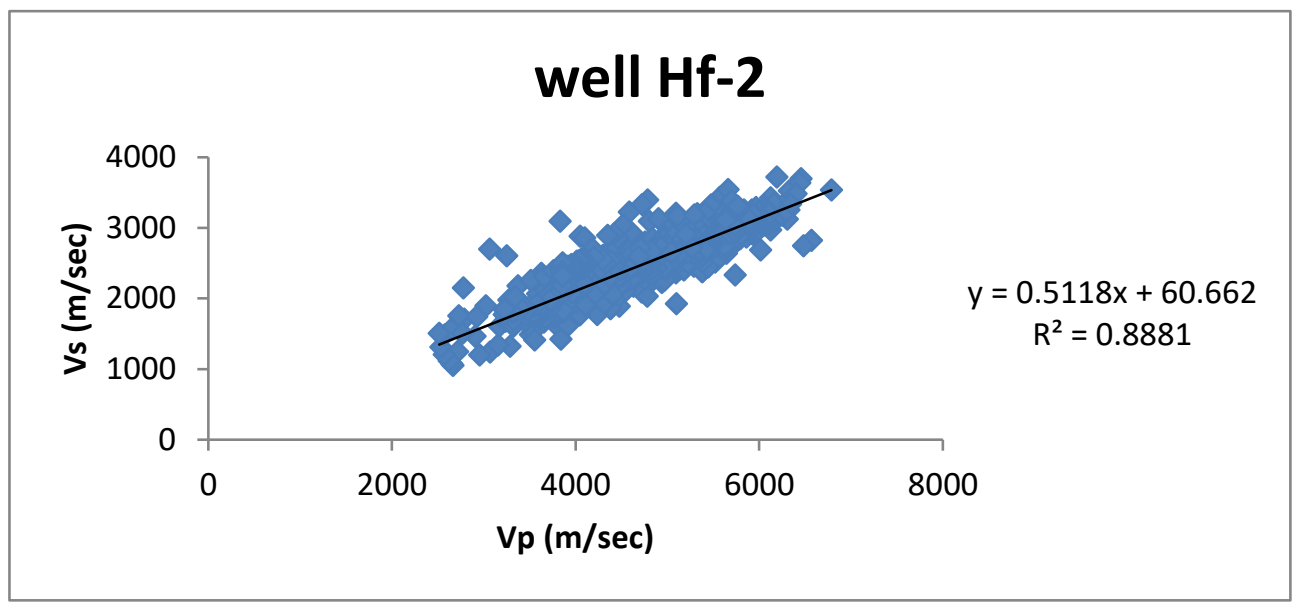

Fig.3.The Vp and Vs relationship obtained from actual field sonic log data at Halfaya oil field. Where $\mathrm{y}$ represents the $\mathrm{y}$ axes $\mathrm{Vs}$, $\mathrm{x}$ represents $\mathrm{x}$ axes $\mathrm{Vp}$ and $\mathrm{R}$ is regression

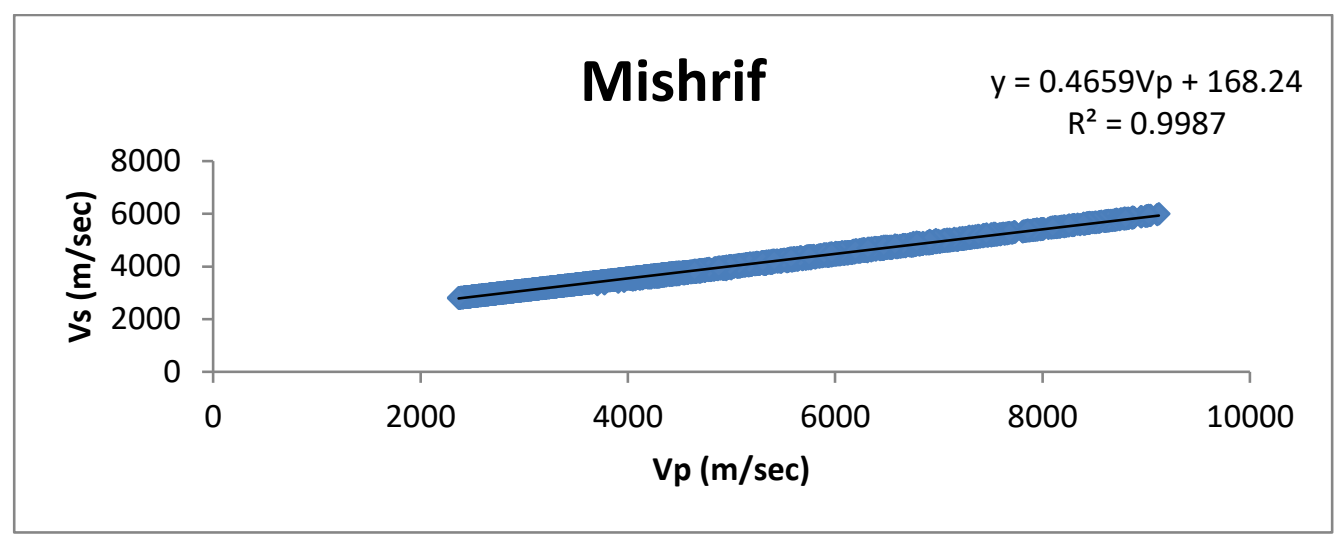

Fig.4.The Vp and Vs relationship obtained from actual field sonic log data for Mishrif Formation at Halfaya oil field

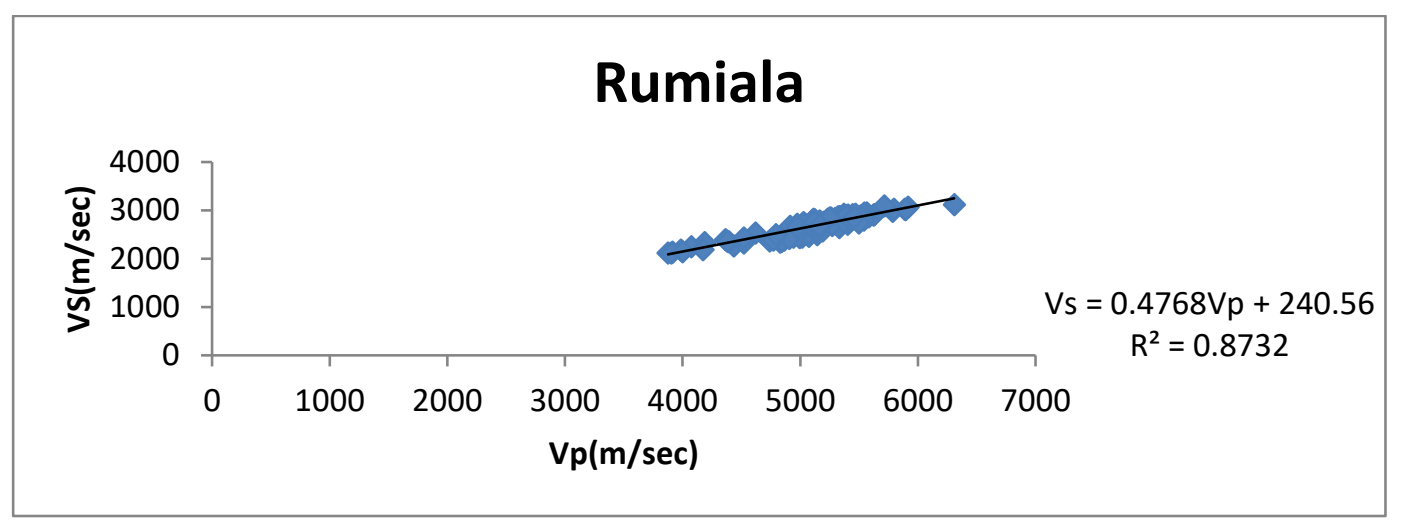

Fig.5.The Vp and Vs relationship obtained from actual field sonic log data for Rumiala Formation at Halfaya oil field south of Iraq 


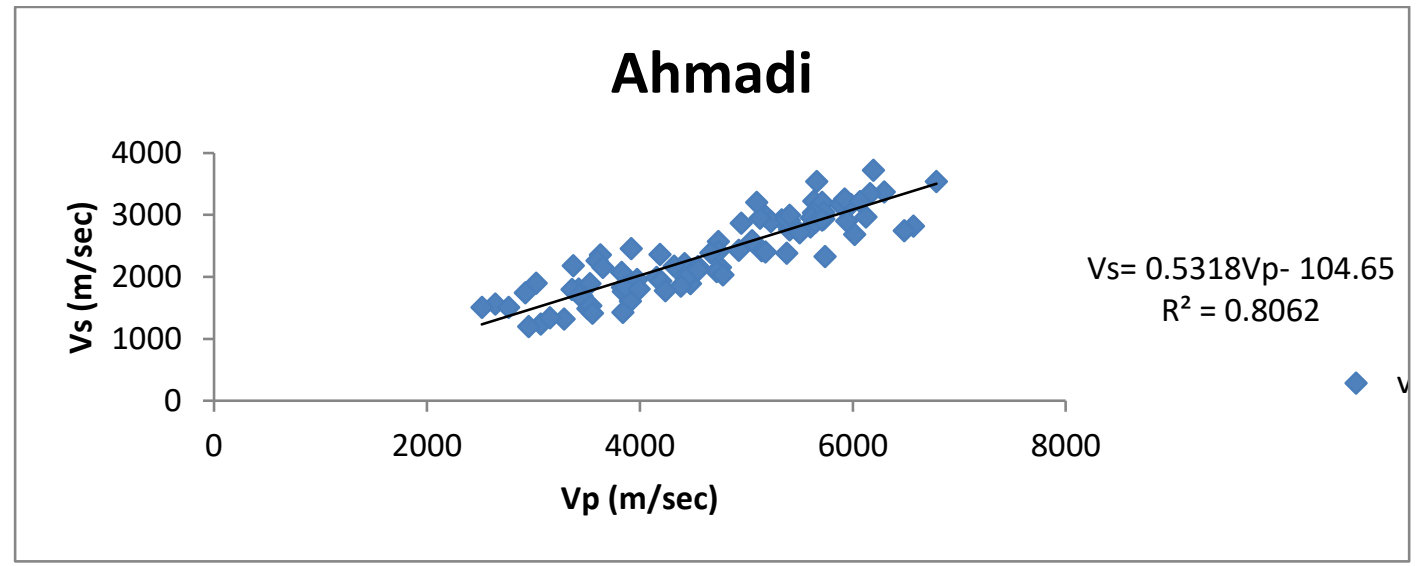

Fig.6.The Vp and Vs relationship obtained from actual field sonic log data for Ahmadi Formation at Halfaya oil field. From this relation we conclude that the existing of high shale volume in this formation cause diffraction in the points and reduce the regression value

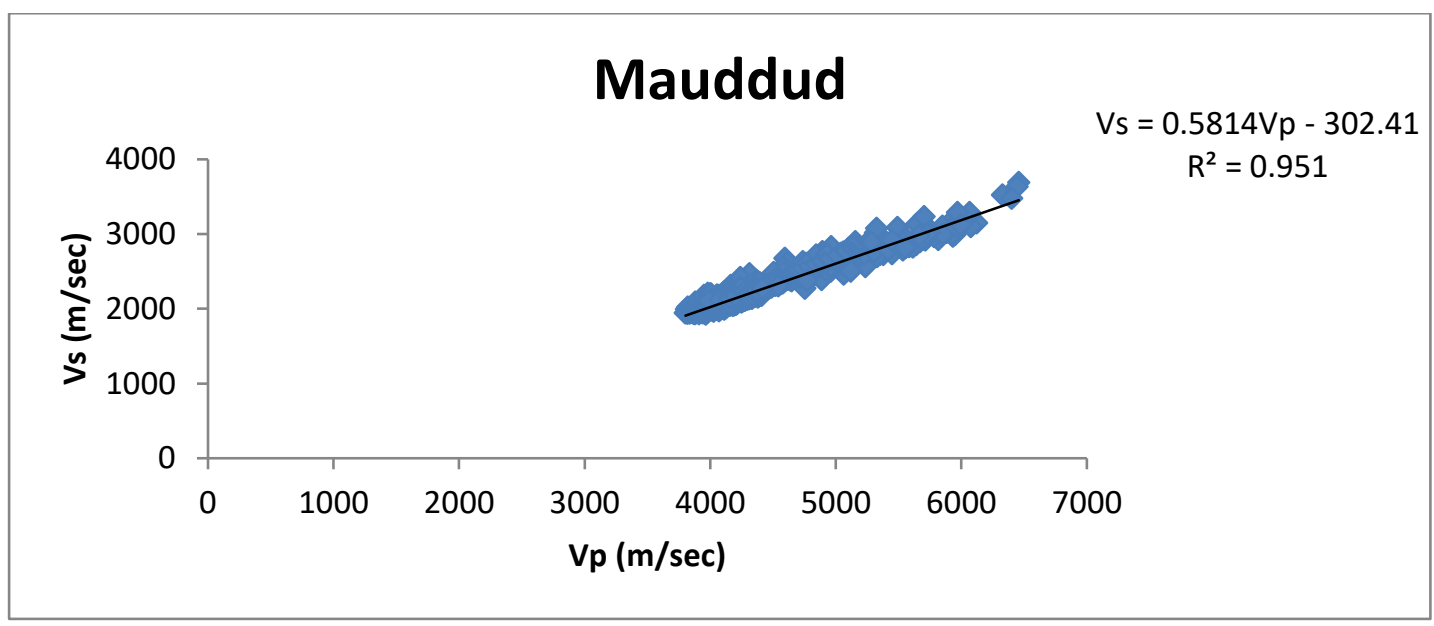

Fig.7.The Vp and Vs relationship obtained from actual field sonic log data for Mauddud Formation at Halfaya oil field

Table1. The equation that is derived for each formation and General equation the well of Hf-2

\begin{tabular}{lcccc}
\hline Formation & Equation & Regression & General equation & Regression \\
\hline Mishrif & $\mathrm{Vs}=0.4659 \mathrm{~V} \mathrm{p}+168.24$ & 0.9987 & $\mathrm{Vs}=0.5118 \mathrm{~V} \mathrm{p}+60.662$ & 0.8881 \\
Rumiala & $\mathrm{Vs}=0.4768 \mathrm{~V} \mathrm{p}+240.56$ & 0.8732 & $\mathrm{Vs}=0.5118 \mathrm{~V} \mathrm{p}+60.662$ & 0.8881 \\
Ahmadi & $\mathrm{Vs}=0.5318 \mathrm{Vp}-104.65$ & 0.8062 & $\mathrm{Vs}=0.5118 \mathrm{~V} \mathrm{p}+60.662$ & 0.8881 \\
Mauddud & $\mathrm{Vs}=0.5814 \mathrm{Vp}-302.41$ & 0.951 & $\mathrm{Vs}=0.5118 \mathrm{~V} \mathrm{p}+60.662$ & 0.8881 \\
\hline
\end{tabular}




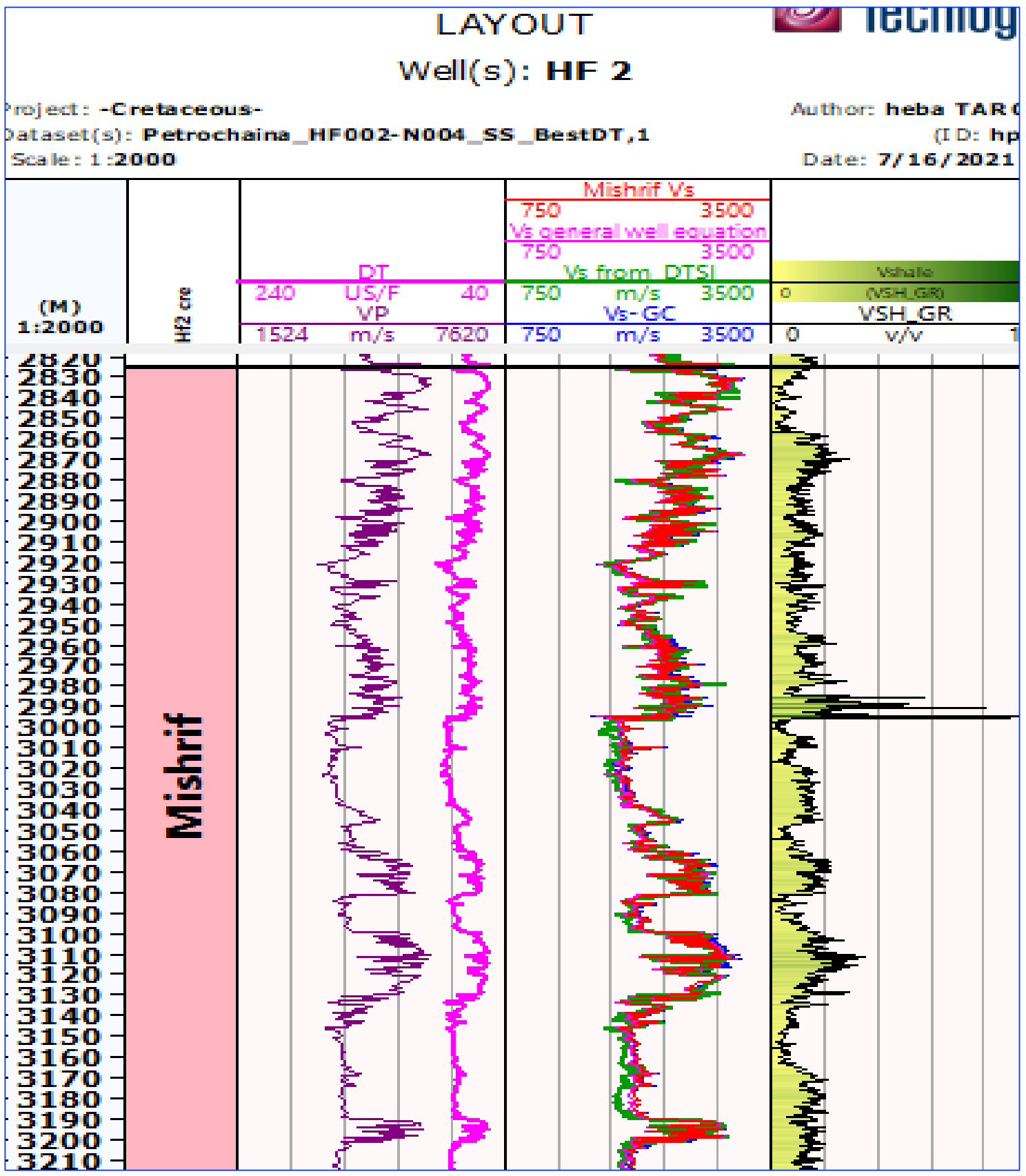

Fig.8. The CPI image represents the distribution of compression wave and shear wave velocities with depth of Mishrif Formation. The general equation obtained for Hf-2 well (pink), spatial formation equation Vs (red), DSI Vs that reflects velocity measured from dipole shear sonic log and Greenberg and Castagna equation (blue) 


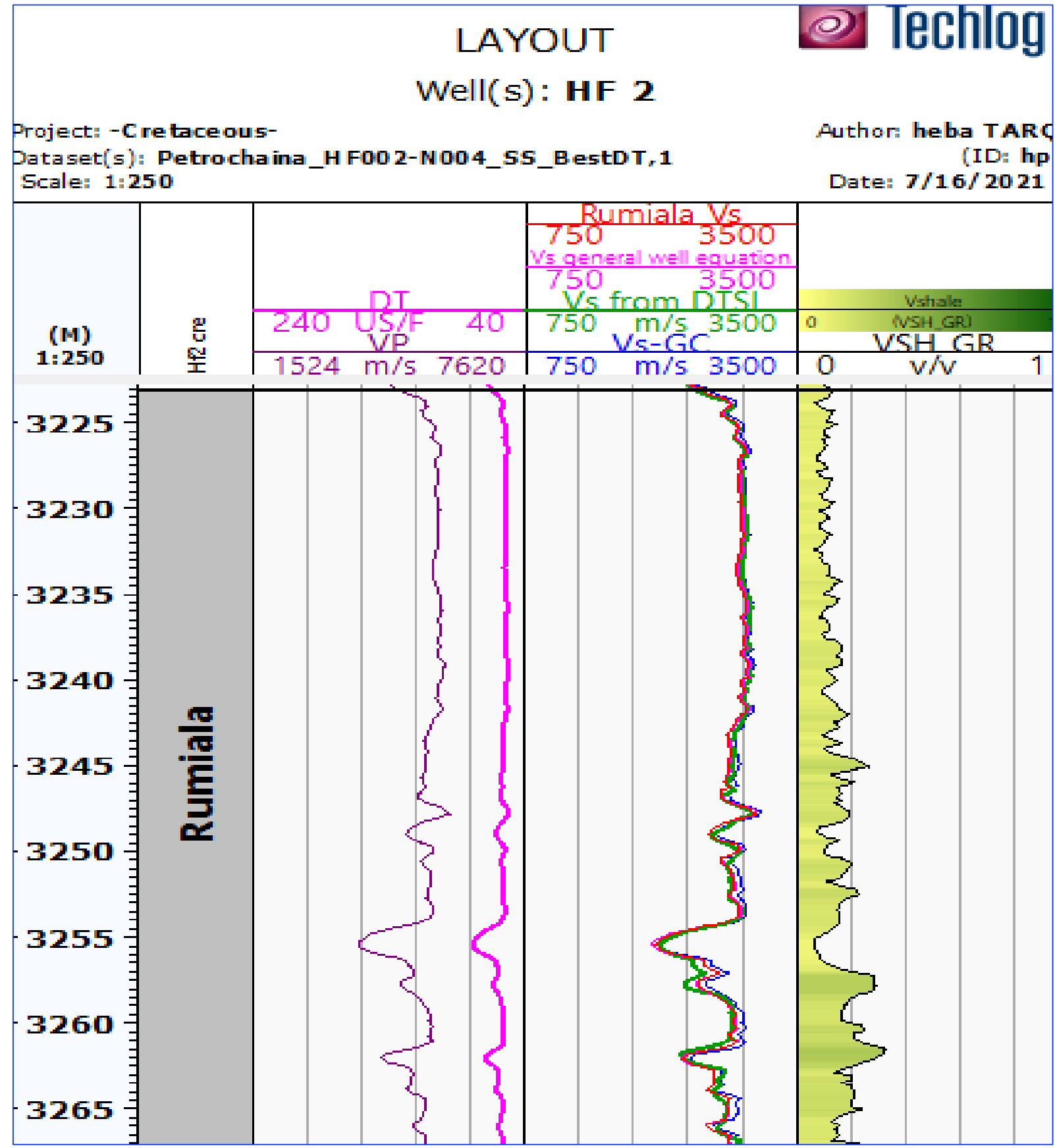

Fig.9.The CPI image represents the distribution of compression wave and shear wave velocities with depth for Rumiala formation. The general equation obtained for Hf-2 well (pink), spatial formation equation Vs (red), DSI Vs that reflects velocity measured from dipole shear sonic log and Greenberg and Castagna equation (blue) 


\section{LAYOUT}

\section{Well(s): HF 2}

roject: -Crebceous-

Author" heba TARQ pataset(s): Petrochaina_HF002-N004_5S_BestDT,1 (IDi hp Scalen 1 ; 200

Date! $7 / 16 / 2021$

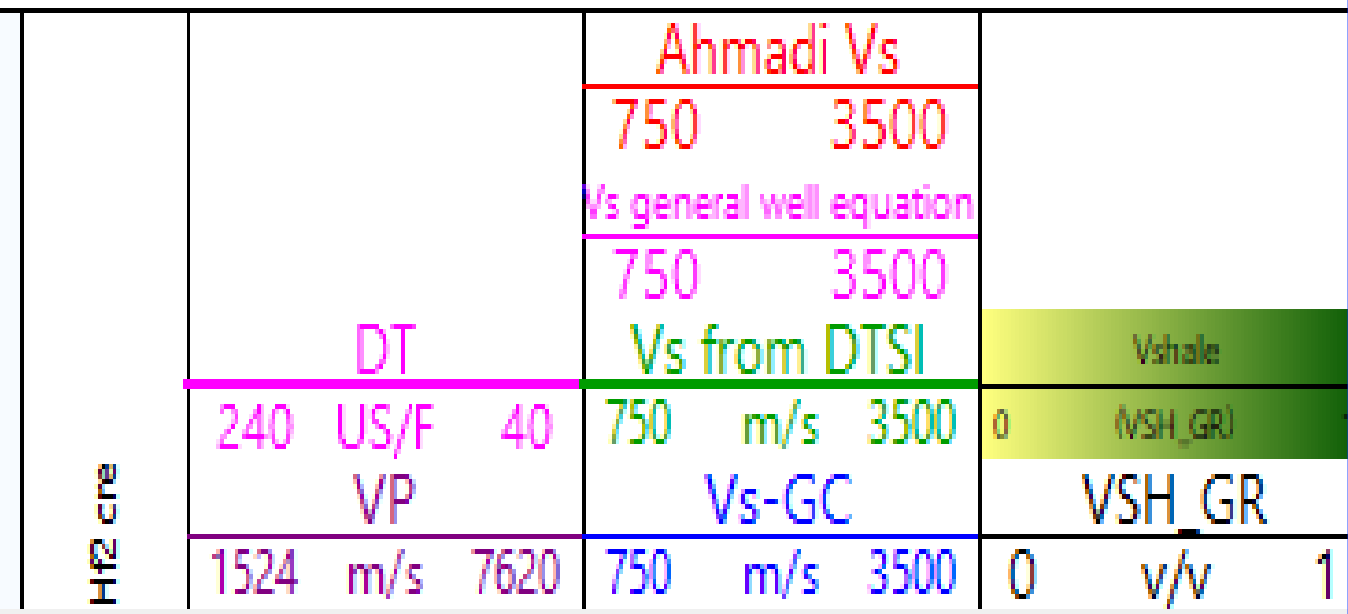
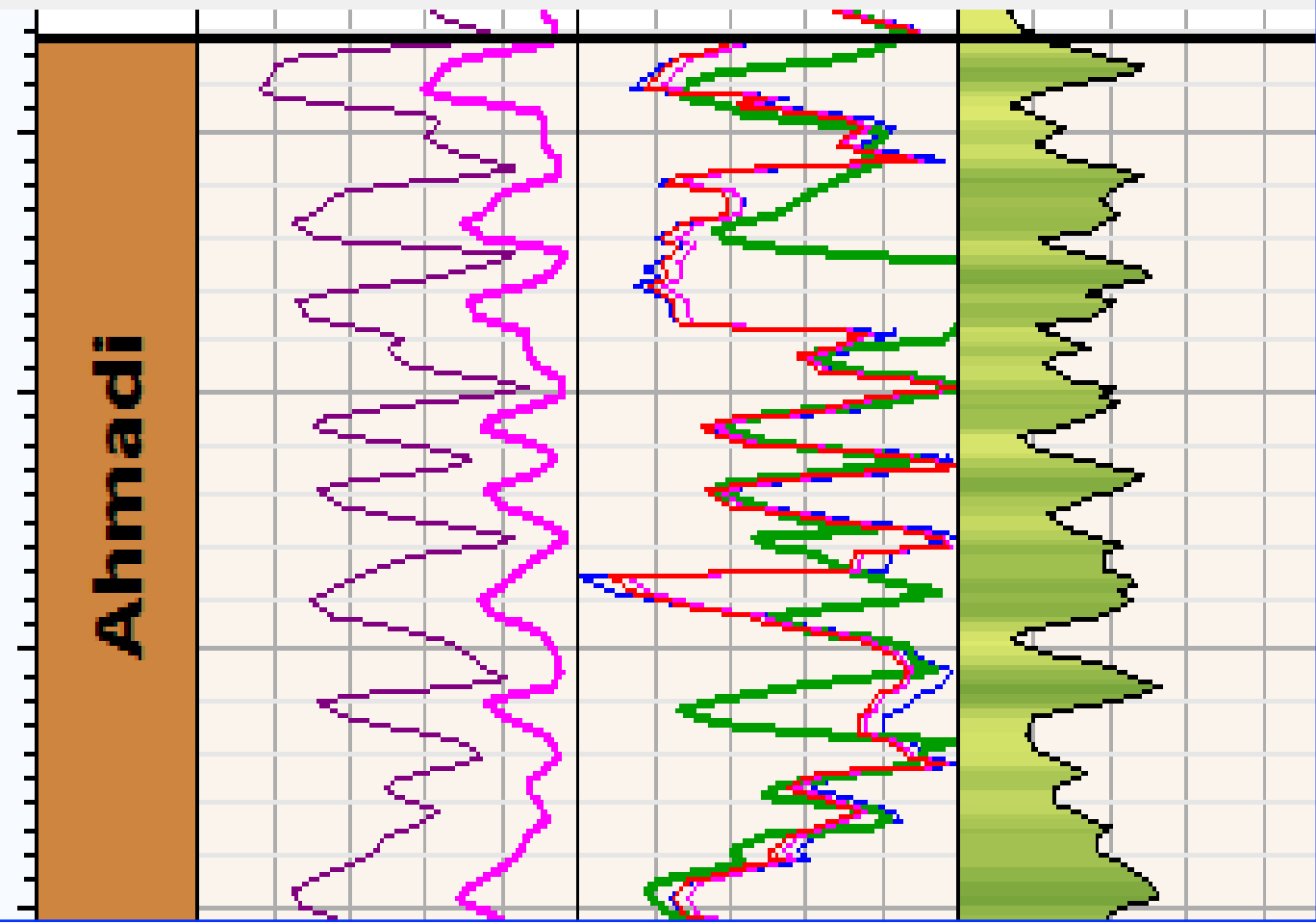

Fig.10.The CPI image represents the distribution of compression wave and shear wave velocities with depth of Ahmadi formation. The general equation obtained for Hf-2 well (pink), spatial formation equation Vs (red), DSI Vs that reflects velocity measured from dipole shear sonic log and Greenberg and Castagna equation (blue) 


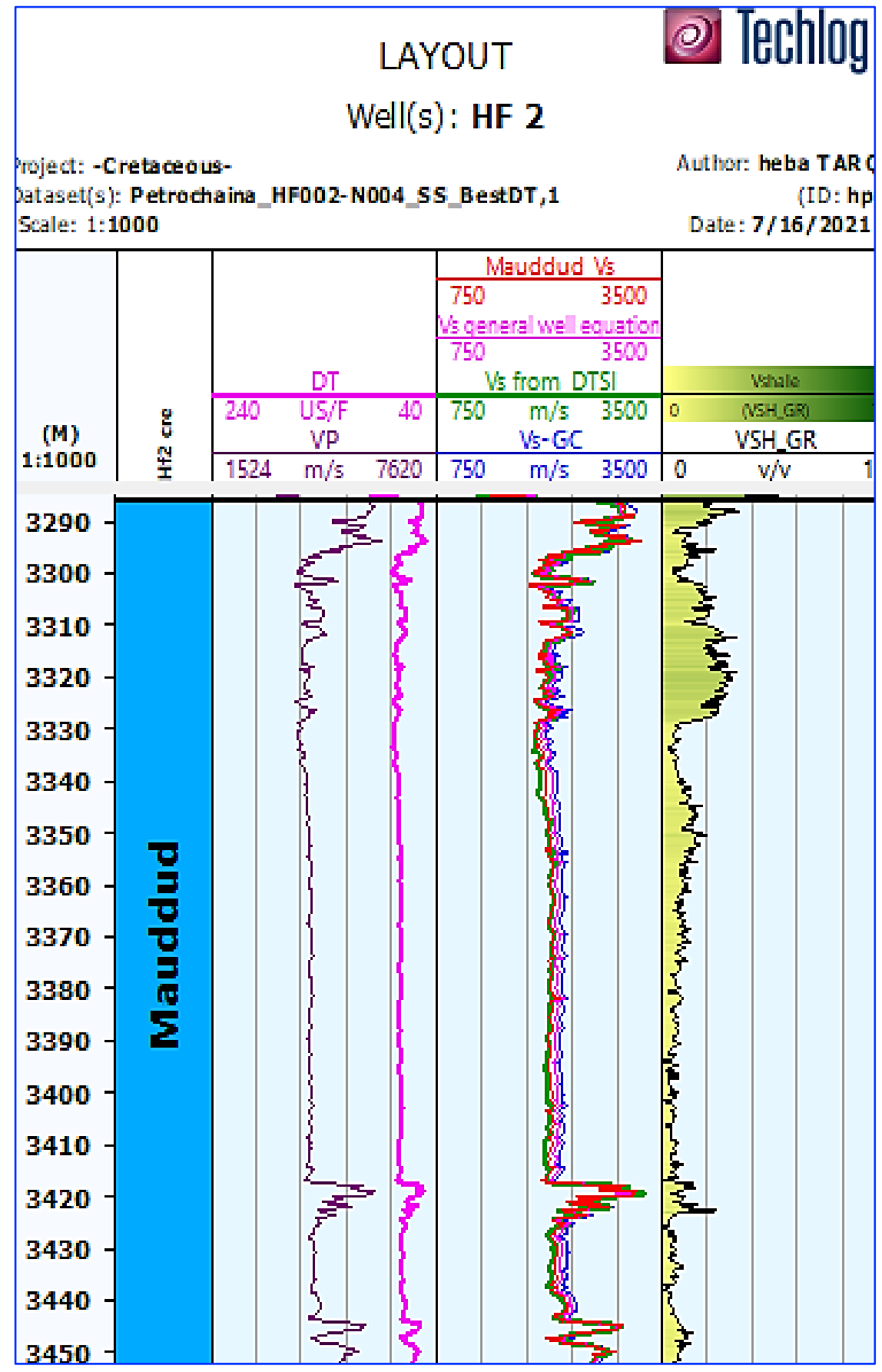

Fig.11.The CPI image represents the distribution of compression wave and shear wave velocities with depth of Mauddud Formation. The general equation obtained for Hf-2 well (pink), spatial formation equation Vs (red), DSI Vs that reflects velocity measured from dipole shear sonic log and Greenberg and Castagna equation (blue)

\section{Conclusions}

This study used the first order least square method to obtain an empirical equation for the considered formations (Mishrif, Rumiala, Ahmadi and Mudded). General equations were obtained for determining Vs from Vp values for all formations in Hf-2 well. Four equations for the considered formations in addition to a general equation for Hf-2 well were obtained. For Mishrif, Rumiala and Mauddud formations, the obtained equations with Greenberg and Castagna equation value are closest to the measured values of DSI Vs in Iraq. While for Ahmadi Formation the three measured velocities 
are consistent each other but there are differences From DSI and Vs. The difference in the Ahmadi Formation may be due to the high percentage of shale volume and high porosities in this formation compared with other formations. The current study confirmed that the obtained equations can be used to determine Vs from $\mathrm{Vp}$ values for the considered formation and those in Hf-2 well and in other regions for all carbonate rock formations in Iraq.

\section{Acknowledgements}

The authors are very grateful to the Ministry of oil, Missan Oil Company for providing the well log data and reports that are necessary to complete this study. The authors are very grateful to the reviewers, Editor in Chief Prof. Dr. Salih M. Awadh, the Secretary of Journal Mr. Samir R. Hijab, and the Technical Editors for their great efforts and valuable comments.

\section{References}

Adjei, F.K., Afari, P. S. A. O., Teddy, A.A., 2020. Estimating shear wave velocity using artificial neural networks: a case study of the TANO north field, southwestern part of Gulf of Guinea.

Al-Khafaji, A., Al-Ameri, T., Abeed, Q., 2013. Oil and gas play and prospect assessments of Babel, Diwania and Karbala Governorates Middle Euphrates Region, Iraq. Arabian Journal of Geoscience, 7(8), 3147-3161.

Al-Malikee, H., and Al-Najim, F., 2018. Indirect prediction of rock elasticity and compressibility strength using well $\log$ data at selected sites within Rumaila Oilfield, Southern Iraq. Iraqi Geological Journal.51(2), 4153.

Amunobereton-ari, I., Omubo-Pepple, V. B., Uko, E.D., 2010. The influence of lithology and depth on acoustic velocities in South-East Niger Delta, Nigeria. American Journal of Scientific and Industrial Research, 1(2), 279-292.

Aqrawi, A., Horbury, A. D., Goff, J., Sadooni, F., 2010. The Petroleum Geology of Iraq, 424pp

Brocher, T.M., 2005. Empirical relations between elastic wave speeds and density in the Earth's crust. Bulltein Seismology Society, 95 (6), 2081-2092.

Castagna, J. P., Batzle, M.L., Eastwood, R. L.,1985. Relationships between compressional-wave and shear-wave velocities in clastic silicate rocks. Geophysics, 50 (4), 571-581

Eskandari, H., Rezaee, M.R., Mohammadnia, M., 2004. Application of multiple regression and artificial neural network techniques to predict shear wave velocity from wireline log data for a carbonate reservoir, South Iran. Can. Soc. Explor. Geophys. 29, 42-48.

Gallo, A., 2015. A Refresher on Regression Analysis. Analytics and Data Science.

Greenberg, M. L., Castagna, J. P., 1992. Shear-wave velocity estimation in porous rocks: theoretical formulation, preliminary verification and applications. Geophysical Prospecting, 40 (2), 195- 209

Krief, M., Garat, J., Stellingwerf, J., Venter, J., 1990. A petrophysical interpretation using the velocities of P and $\mathrm{S}$ waves (full wave from interpretation using the velocities of $\mathrm{P}$ and $\mathrm{S}$ waves (full wave from sonic). $\mathrm{Log}$ Analysis, 31, 355-369

Majeed, R.K., Alhaleem A.A., 2020. estimation of shear wave velocity from wireline logs data for Amara Oil field, Mishrif Formation, Southern Iraq, Iraqi Geological Journal, 53(1A), 36-47.

Messan Oil Company (M.O.C), 2012. Final geological report for Hf-2. Geology Department., Ministry of Oil, Messan, Iraq.

Messan Oil Company (M.O.C), 2013. Final development plan of Halfaya contract area, Geology Department. Ministry of Oil, Messan, Iraq.

Opiriyabo, I. H., Valentine, B.O., Iyeneomie, T., 2014. Estimation of shear wave velocity for lithological variation in the north-western part of the Niger delta basin of Nigeria. American Journal of Scientific and Industrial Research, 5(1), 13-22

Rezaee, M.R., Kadkhodaie, I., A., Barabadi, A., 2006. Prediction of shear wave velocity from petrophysical data utilizing intelligent systems: an example from a sandstone reservoir of Carnarvon Basin, Australian Journal. Petroleum Science Engineering, 55(3-4) , 201-212. 